\title{
Reflective questions, self-questioning and managing professionally situated practice
}

\author{
Richard Malthouse \\ Jodi Roffey-Barentsen \\ Mike Watts
}

\begin{abstract}
Reflective self-questioning arises within the work-place when people are confronted with professional problems and situations. This paper focuses on reflective and 'situated reflective' questions in terms of self-questioning and professional workplace problem solving. In our view, the situational context, entailed by the setting, social and personal/individual perspectives, is interactional. The supporting empirical data is drawn from our work with two groups in their tertiary phase of education: professional trainers within a large corporate organisation and para-professionals within a large college system; each embraces phenomenological principles. The discussions of situated reflective practice (SRP) entail those circumstances where change is visited upon the individual by forces outside their immediate control. The positive sense of SRP is that it can prepare an individual for anticipated change, and is therefore considered a method of change management. The situation acts as a catalyst for the thought.
\end{abstract}

Key words: Reflective questions, self-questioning, situated reflective questions, situated reflective practice, work-place problems

\section{Introduction}

This paper brings together two distinctive aspects of reflective practice. The first draws upon a considerable body of work on the nature of questions and questioning (Pedrosa de Jesus, Watts \& Lopes, 2009; Watts \& Pedrosa de Jesus, 2006). The second relates to a mode of individual reflection termed 'situated reflective practice' (Malthouse, 2012; Malthouse and Roffey-Barentsen, 2013; Malthouse, Roffey-Barentsen \& Watts, 2013, in press). The overlap of the two promises to provide valuable insights into personal and professional reflective practice. The purpose of the work we discuss is to draw upon a phenomenological perspective to examine our respondents' situations, and to see these 
as 'profound centers of human experience' (Cresswell, 2004: 23). There is no implication that, from such a phenomenological perspective, these respondents are passive in the creation of the situations they report; to the contrary, the relationship between self and situation is dynamic, where people and work-place both play an active role. Our intention is to add to conventional notions of reflection where particular situations operate to shape these trainers and educators, and influence the ways in which they think about and frame social relationships, professional change and development. At the same time we are interested in how these professionals act and react, how they question and problem-solve when faced with circumstances changing around them. Ours is a reflexive approach to 'situation', one that may help educators to be more mindfully about in they frame and assess the complex challenges that arise when initiating social change.

\section{Reflective questions}

In this first section we focus on the questions that prompt reflection and that can, in turn, be prompted by reflective acts. Reflection is a process that can be described as thinking about one's own thinking and actions (Schön, 1996). Several mechanisms are involved in this 'thinking about thinking' entailing, for example, controlled monitoring, analysis and re-analysis of one's own problems and problem-solving process. In this sense, we describe reflective questions in terms of their capacity to stimulate, or arise as the result of deliberation, introspection and contemplation. They can be formed through variance between formulations and expectations of experience and what is then perceived to have taken place. The respondents throughout our research have been students in the tertiary phases of education. The core of the data we describe has been generated in interviews exploring professional practice, sometimes moments of reflection prompted in response to interview questions, sometimes when respondents have asked questions of themselves and then duly answered them. Brockbank \& McGill (2000) suggest that questions become reflective when emergent ideas are related to existing senses of knowledge, self and the world, and as new understanding emerges. Their examples of reflective questions are:

'Something is happening that surprises me. It is not usual, but what is it about?'

'Is what I am doing appropriate at this moment?'

'Do I need to alter, amend, change what I am doing in order to adjust to changing circumstances to 'get back into balance'?' 
'If I am not on the right track, is there a better way of doing this?'

The existing literature on reflective questions and questioning is relatively thin beyond, that is, such lists of exemplar reflective questions ready-made for practitioners to ask of themselves, but which have little basis in theory. One clear thread in the work that does exist is that reflective questions are seen somehow to be more deep-seated, more primary, than other kinds so that, in 1992, Smyth suggested that reflective people ask of themselves more 'fundamental' questions; Van der Meij's (1994) strongly proposed that questioning prompted by reflections leads to 'deeper' questions and, in a similar vein, Korthagen \& Vasalos (2005) described such questions as bringing about 'core reflection'. A second thread explores the value of reflective questions over other kinds. Bourner (2003), for example, argues that one reason some people are poor at reflective learning is that they have at their disposal only a limited repertoire of searching reflective questions, and both King (1994a) and Rosenshine et al. (1996) show that, when present, self-questioning is the most effective monitoring and regulating strategy of all the various meta-cognitive strategies they examine.

In our view, then, reflective questions require people to examine their existing knowledge or information before giving a thoughtful response, to delve further into their knowledge, experiences or views. The value and importance of reflective questions lies within the asker: the sole beneficiaries of reflective questions are the respondents, it is they who have a stake in the answer.

\section{Self-questioning}

One form of reflective questioning rose to prominence in the 1980s and 90s under the label 'self-questioning'. This area of work predominated in studies of textual analysis, comprehension of texts and narrative, and the production of writing. In this sense, selfquestioning is regarded as a cognitive, rather than a meta-cognitive, strategy that can help students focus attention, organise new material and finally integrate the new information with existing knowledge (Doerr \& Tripp, 1999; Glaubman \& Ofir, 1997; King, 1992; Wong, 1985). The intention is that novice information analysts ask the right questions to themselves, learn how to think like an expert and, eventually, organise their knowledge like an expert.

One strand of this work uses Schema Theory as the basis for discussing selfquestioning. According to Carrell \& Eisterhold (1983, cited by Mckay, 1987) 
formulating questions about a particular text activates the reader's schema, thereby facilitating the connection between what is already known and the new information in the text, 'comprehending a text is an interactive process between the reader's background knowledge and the text' (p. 18). From this perspective, constructing selfquestions involves decisions on what information is question-worthy (Frase \& Schwartz, 1975), and self-questioning 'places the responsibility for learning on the students, increases attention, and allows students to take corrective action' (Harris \& Sipay, 1985, cited by Gillespie, 1990, p. 253).

More recently, self-questioning has been revived in a broader sphere, in relation to work-place problem solving. Cho \& Jonassen (2002), for example, have argued that self-questioning is likely to improve participants argumentation by focusing and orientating their attention on relevant information and facets of a particular problem, helping them to make better connections and making their thinking more explicit during their reasoning process. Koa Heng Ng et al. (2011) have examined the effects of selfquestioning techniques on ill-structured professional problems and showed that the use of self-questions had significant positive effects on reasoning performance and overall problem solving performance. The sense of this work is that self-questioners will be more aware of the assumptions they were making, can reflect and check for 'blind spots' in their thinking. The kinds of self-questions that arose were,

'Is there a good way?'

'Is there a better way?'

'What will happen?'

'What are the consequences?'

This latter direction impinges on our own specific interests. We are less concerned with a local focus on text and textual analysis, but certainly veer towards broader professional activity and approaches to workplace problems. We are keen to explore more fully the relationship between self-and-world: in particular those situations where respondents are testing their personal sense of agency. Our concerns lie in the struggles of our participants as they wrestle with the structural constraints of their professional field, their self-examination and self-questioning that entails their capacity to recognise forces of socialisation and shift their place in the organisational structure (Giddens \& Pierson, 1998). That struggle commonly revolves around the construction, formulation and then articulation of the 'important' or 'key' question that relate to particular 
problems that are encountered, and which foments essential reflections on practice. Boud \& Miller (1996) argue that reflective learning occurs within a framework of taken-for-granted assumptions about what is legitimate to do, to say and even think. It is influenced directly and indirectly by the powers of others as well as by forces, which constrain participants' views of what is possible. Our direction here is to explore the ways reflective questions unearth those assumptions.

\section{Professional work-place problems}

Problem solving is an important aspect of professional practice (Bereiter \& Scardamalia, 1993). Professionals rely on their problem-solving skills to handle the increasingly ill-structured nature of their work (Schön, 1987). Schema Theory is again invoked to enable quick movement from the identification of a problem to the selection and implementation of solution procedures (Bereiter \& Scardamalia, 1993). The activation of particular schemata reduces the amount of mental resources that a person requires to deal with a problem, thus increasing his or her mental capacity to attend to the important problem-details. Increased professional experience brings sophisticated schemata that shape the goals, facts, constraints, solution procedures, and possible solutions related to particular problems (Chi \& Glaser, 1985; Chi, Glaser \& Farr, 1988; Larkin, McDermott, Simon \& Simon, 1980; Palumbo, 1990).

Our sphere of activity is education and, as authors, we bring together a range of different educative processes from professional training within a large corporation, teaching and learning at university level, the training of classroom teachers and the development of 'para-educators' such as classroom assistants and education officers in non-formal settings. For example, our students may use reflective questions in order to prepare for job interviews, reflect on skill development or when undertaking personal development planning (PDP). In this context, reflective questions serve to stimulate the students to reflect on the skills that they are practicing, to raise self-awareness and the ability to articulate these skills. Through these, they become familiar with competencybased interviewing and assessment,

'Reflect on a situation in which you had to adjust to changes over which you had no control. How did you handle it?'

'Think about a problem that you have solved in a unique or unusual way. What was the outcome? Were you satisfied with it?'

'What do you do when priorities change quickly? Thinking about an example of 
when this happened, what did you do? What was the outcome?'

Within our educational domain problems are commonly decided by purpose, a problem arises when a problem-solver cannot realise a purpose, and an educative purpose can be radically different between two professionals, where they might see the same situation in quite different ways. The articulation of the problem often entails expressing a broad solution:

'If you had a wish to make the problem disappear, what would it be?'

In such circumstances, both moral and emotional dimensions are usual, and essential. Educators commonly judge whether a situation is right or wrong based on the participants' moral standpoint and emotional commitment:

'Does it feel right?'

'Is it fair?'

In this form of problem-solving, the problem situation can be very ill-defined, and there may be very few acknowledged solutions (Watts, 1998; Watts \& Pedrosa de Jesus, 2006). This kind of problem solving is not necessarily logical or rational: creativity and flexibility are important aspects. For example, beginning to tackle a problem is deemed better than not-starting, even if the solution is an open-ended trial process and seen to be exploratory or 'work in progress'. Solutions are commonly empirically-based, experience of a similar situation from before, or elsewhere, is used as a comparator knowledge base,

'Shouldn't we start from what we can do?'

'Can we not try to fix the essential problem first?'

\section{Situated reflective practice (SRP)}

Situated Reflective Practice offers a different perspective to that of the traditional forms of reflective practice because it concerns with the ways in which people, a social group or an organisation behave, and the impact these have upon a reflective individual, as opposed to the simple to considerations of his or her directed actions. The distinction between Reflection-re-Action, Reflection-re-Inaction and the more familiar Reflectionin-Action or Reflection-on-Action is that the focus of attention of SRP might be far removed from the person experiencing it. The essential quality of SRP is concerned 
with the changes in, or the emergence of a situation that, through only part design, action or behest of the perceiver, affects that individual in significant ways. In other words, it focuses upon external events that creep into our lives, commonly uninvited, or form part of the institutional structures to which we subscribe when taking a professional role. Although often, but not exclusively, 'situations' relate to the ways in which a social group or an organisation is behaving, it can also relate to the more traditional examples of reflective practice that feature, for example, within classrooms or other learning and teaching arenas. While it is certainly aligned to aspects of selfdirected professional development (Minott, 2010), the critical difference here is the influence of a pressing external context that impacts upon an individual, as opposed to people reflecting upon something that they have done themselves, something for which they are, or have been, fully responsible. They may have 'put' themselves in that position but subsequently have little control over the situation in which they are participating. In fact, the perceived situation may not actually be affecting them; at least not at that particular moment.

Much of the discussion of the nature of reflective practice has focussed on the intensely subjective 'internal worlds' of reflective practitioners. 'Reflection in action' and 'reflection on action' are those reflective episodes where there is 'thinking with a purpose' (Moon, 2005), the rumination, cogitation and deliberation on particular issues as a means of sorting complex and ill-structured thoughts, perceptions, ideas. The purpose behind the act of reflection is to reduce the complexity, and hence the unpredictability, of the issues involved, to find a route out of the complexity. In these pictures of reflection, little is actually made of the broad context, the situation, in which the person finds themselves.

Our notion of SRP (Malthouse, 2012; Malthouse \& Roffey-Barentsen, 2013; Malthouse, Roffey-Barentsen \& Watts, 2013) builds on ideas from Schön (1983), Kolb (1984), Gibbs (1988), and seeks to add to the body of knowledge in a way that enables people to make sense of their world by observing the prevailing extended or external influences. It does not seek to replace the traditional ideas in relation to reflective practice, but to add to them. Elsewhere, we (Pedrosa et al., 2011) have delineated a situational context as being entailed by the:

(i) Setting: the broad location, the physical environment, the surroundings, the time, systems, access and availability of information, the ambiance; 
(ii) Social: the learning community, its history, ethos, the roles, responsibilities, relationships, tasks, expectations, other people, what the participants are actually doing, their goals, the activities involved;

(iii) Personal/Individual: individual dispositions, skills, competencies, participants' mental and physical states, intentions, moods, engagement, expertise.

Our noted above, sense of situational context is interactional: in professional settings, context is a relational property among people, place and activities. This view argues that the scope of contextual features is defined dynamically, context is relevant to particular settings, instances of action and particular parties to that action: context and activity are not separable. That is, context, situation, is embedded in activity and arises from it. Taking the interplay of these elements one at a time:

(i) Setting: The physical surroundings are important. A hospital ward brings its own pressures for a nurse; a raked auditorium for a novice lecturer; a night-lit street for a new police constable; a motorway hard-shoulder for a young paramedic, a disreputable-looking squat for a youth worker. In our sense of 'situated reflection', it is a mistake, an over-simplification, to assume that reflection is agnostic to the physical settings in which professional life takes place.

(ii) Social: A social context is also task-dependent. For students to listen and take notes in lecture mode is different to working at small-group mini-projects or making a presentation to a class of peers; a laboratory worker undertaking a labbased experiment is different to conducting off-site fieldwork. In each of these, the 'relational formality' within employment hierarchies, and also between peers, is different and provides different task-contexts in which reflection takes place (or not).

(iii) Personal/ Individual: It is part of the overall discussions of reflective practice that people can be seen to have discernible styles of reflection. Moon (2005), for instance, discusses 'depth' as a dimension of reflection, while others (e.g. Bleakley, 1999; Åkerlind, 2007; Bell \& Mladenovic, 2013) discuss breadth, complexity, levels of control, and so on. Our sense of situated reflection is that individuals respond in different ways to the situations in which they operate, so it is not just the 'reflective style' that matters, but also the person's perceptions and appreciation of the situation. 
Situated Reflective Practice, then, offers a different perspective to that of the traditional forms of reflective practice because it is concerned with the way in which people, a social group or an organisation is behaving, and the impact this has upon a reflective individual, as opposed to the simple considerations of his or her directed actions. It promotes reflection upon something that might happen, commonly as a result of the way in which a social group or an organisation is functioning and the impact this may have. The focus of the action may not directly be on the person who is reflecting upon the potential impact of that action on themselves. They may not have any control over the situation of which they have become aware. Furthermore, there is the possibility that the anticipated impact of the situation may not affect them, or at least not at that moment. There are five distinct characteristics of Situated Reflective Practice, these are described as:

1. A passive observation of a phenomena

2. Experienced by proxy

3. Found in social/organisational situations

4. Can occur at the time or after

5. The locus of power being separate from the person experiencing it.

Malthouse (2012:371)

We illustrate some of these through the examples discussed below. However, the following table indicates which characteristics are evident within each example:

\begin{tabular}{|l|c|c|c|c|c|}
\hline & $\mathbf{1}$ & $\mathbf{2}$ & $\mathbf{3}$ & $\mathbf{4}$ & $\mathbf{5}$ \\
\hline Example 1 & $\sqrt{ }$ & $\sqrt{ }$ & $\sqrt{ }$ & $\sqrt{ }$ & $\sqrt{ }$ \\
\hline Example 2 & $\sqrt{ }$ & & $\sqrt{ }$ & $\sqrt{ }$ & $\sqrt{ }$ \\
\hline Example 3 & $\sqrt{ }$ & & $\sqrt{ }$ & $\sqrt{ }$ & $\sqrt{ }$ \\
\hline Example 4 & $\sqrt{ }$ & & $\sqrt{ }$ & $\sqrt{ }$ & $\sqrt{ }$ \\
\hline Example 5 & $\sqrt{ }$ & $\sqrt{ }$ & $\sqrt{ }$ & $\sqrt{ }$ & $\sqrt{ }$ \\
\hline Example 6 & & & $\sqrt{ }$ & $\sqrt{ }$ & $\sqrt{ }$ \\
\hline
\end{tabular}

Table 1 Characteristics of SRP as found in the examples 


\section{The broad research approach}

Our key interest, then, is the exploration of the reflective self-questioning that arises within the work-place when people are confronted with professional problems and situations. These reflective questions are constructed sensitive to the individual involved, the setting and the social context in which the problems occur, and to the likely feedback they might elicit.

Like other educational researchers (e.g., Marton, 1981; Roth, 2004), we have been influenced by ideas from within phenomenology (Malthouse, 2012). The thesis that living beings constitute experience has been extensively explored in continental philosophy (Heidegger, 1996; Husserl, 1992). Originally, Husserl 'envisaged phenomenology as the descriptive, non-reductive science of whatever appears, in the manner of its appearing, in the subjective and inter-subjective life of consciousness' (Moran, 2008, p. 2). After a century of development phenomenology is extraordinarily diverse, with nearly as many 'versions' as major contributing philosophers, full of mutually inconsistent accounts, divergent lines of inquiry, and linguistic labyrinths. This diversity, characteristic of all living philosophical strands, makes apparent that what we do in this paper responds to a particular take on phenomenology. We take the inter-subjective world of the participants as the domain of study. The intent of the work is to generate rich, evocative descriptions of lived teaching experiences, enabling insight into someone else's (as well as one's own) subjectivity. Our aim is not to postulate causal mechanisms but to grasp 'what the experience is like' for the participants. We are not aiming to find ultimate causes motivating utterances and interactions, nor trying to establish a basis for deterministic predictions in other subjects or circumstances. The contribution we hope to achieve is to act as 'empathetic others' within a conversational research approach, to enrich the perception of the nature of the participants' experience. We want to grasp what it was like for them to be there. We think that a richer understanding of how certain people felt and acted in complex episodes can allow one to broaden one's sensitivity to nuances otherwise condemned to oblivion, to question one's own assumptions, and to envision new possibilities for teaching and learning. As noted earlier, our empirical data here is drawn from our work with two educational groups in two main fields: professional trainers within a large corporate organisation $(\mathrm{RM})$, and para-professional training within a large college system (JR-B). 


\section{Example 1. Corporate re-organisation, 'Will this affect me?'}

(i) The setting: there was a need to make cost-cutting manpower reductions in the corporation's budget. In this case, although the employment regulations in the organisation had not been changed, they were being enforced in a different way. These changes were being observed by Patrick,

Patrick: We have got people who have been told, as has happened twice this week, "You have reached 30 years' service. You are only 52 - but here is 28 days' notice. We don't want you anymore." These are people who are too expensive. The management has now introduced one of the pension regulations that says, if they have nowhere else for you to go in the system, regardless of your age, you can be got rid of. So will this affect me?

(ii) The social context: Many of the people within this corporate organisation may have anticipated working beyond 30 years and were now faced with possible retirement at that stage. This entailed the need to consider retirement at a much younger age with profound effects on their life-choices and long-term planning. While these changes in the use of the regulations were not widespread at that moment, it also meant that the implications were not tested and clear.

(iii) The individual person: Patrick was clearly in the position of having served thirty years with the corporation, and so the changes affected his situation. Such a professional problem would have certainly exercised considerable reflection, resulting in the question, 'So will this affect me?' Here, Patrick concerns himself with the implications of the possibility that he may be forced from his current employment. The question engenders considerations in relation to future plans.

\section{Example 2. A special pupil moves school: 'What will I do?'}

The setting: In mainstream schools, Special Needs Assistants are often contracted to work specifically with a particular child (usually pupils with a Statement of Special Educational Needs). One participant in our research explained that she had lost a previous job because the pupil with whom she worked had transferred to a different school. As she talked about this, a colleague realises that this could also happen to her, Brenda: I'm a special Needs Assistant; if she [the pupil] leaves, then I'm out of a job. Then what would I do? 
The social context: As with Patrick's case above, this example relates to possible loss of employment. In this situation, the loss would not arise as a direct consequence of costcutting within an organisation, but simply because the particular target of this assistant teacher's expertise might relocate and so remove the need for her skill and expertise. The school system can rarely afford to employ un-allocated support help of this kind.

The individual person: The situation has not actually occurred as yet and so is anticipatory. Brenda is reflecting upon the possibility of the organisation, in this case the school, ceasing her contract as a result of a situation that is not within her control. Like Patrick above, she may want to consider plans for alternative employment, should the situation arise.

\section{Example 3. A loss of adjunct services: 'What happens now?'}

The setting: The following example represents a consequence of changes in organisational practice, again associated with cost-cutting,

Alan: I am the deputy for community engagement. We do training in motivation and first aid for a local mosque, which is outside the main part of our job. Well that's all going to go out of the window now, because we can no longer do community engagement... because there is not the time, the money or the will. The question is what is going to happen to community relations now because of this?

The social context: Here the loss of the community engagement appears to have come about as a consequence of the financial restraints enforced by the corporation and its clients. As a result, the lack of community engagement could potentially lead to a detrimental effect on corporation /community relations and is a position that appears to generate situated reflection.

The individual person: Again, a significant feature of this example is that it is anticipatory in nature. In fact at that time no detrimental effect on corporation/community relations had actually been identified.

\section{Example 4. My child misbehaves: 'How can I deal with that?'}

The setting: It is not uncommon that some Teaching Assistants (TAs) are employed by the school that their own children attend. On occasions, they can actually be working in their own child's classroom. Although working at the same place is generally regarded 
as 'parentally convenient', it can create professional tensions, particularly if the TAs own child is the one to misbehave,

Fiona: I think it's a bit funny working in the same class where my child is. You see too much and to be honest, I find it difficult not to keep an eye on my little boy all of the time. I know he can be a bit boisterous but I don't want him to make a fool of himself. Or, hmmm... of me really, in front of the teacher and all that. It's embarrassing, especially if the class teachers then talk about it in the staffroom. It would make me feel bad and inadequate. How would I deal with that?

The social context: This example concerns a group of individuals rather than an organisation. Fiona is anticipating how she would react to colleagues discussing her son's behaviour and how she would cope with that - not least the social embarrassment. The individual person: Although Fiona finds it challenging not to 'keep an eye on' her son, the situation is not within her control.

\section{Example 5. Twice the workload: 'How will I cope?'}

The setting: The following account relates to budget reductions introduced as a direct consequence of the government demands for financial savings. Tom works within the corporation's training unit. He is aware that changes to his working conditions are imminent and has been questioning the possible changes,

Tom: Looking forward you know, I anticipate that huge changes are just around the corner. In this department we have been seriously impacted upon by budget cuts, which are now corporation wide. At a stroke, my work load has effectively doubled, because now I will effectively have to deliver twice as much training because we are being cut in half as a training unit. How will I cope with the workload?

The social context: Tom describes the uncertainty of his situation, uncertainty that exists as a result of a reduction in funding for the training budget. Tom has no control or influence upon funding for his unit. Further, it is unlikely that the corporation's Senior Management Team (SMT) has much control over funding issues, since the decision to reduce funding will be taken at a much higher level within the organisation. The root cause of the situation is a combination of reduced funding and, arguably, poor management of people; uncertainty engenders has a direct effect on anxiety and morale. 
The individual person: Tom expressed some relief at still being employed within the unit, but he is aware this could be short lived. This example of Situated Reflective Practice identifies that although this individual is aware of the emerging changes,

\section{Example 6. Too much information: 'How should I respond?'}

The setting: In some instances, TAs can be regarded as more approachable than regular classroom teachers. They commonly live in the local community and may know many of the other parents/ carers whose children attend the school,

Gina: My problem is that the child's mother is a sort of friend of mine. Her oldest daughter was at the same playgroup and nursery as mine, we've known each other for years. But I can't talk to her about anything at work, because that would be unprofessional, you can't have a bit of a gossip. Sometimes I know things about the school or teachers, but I just can't talk about that. You know, things about children and families that you have to keep them to yourself. But sometimes the other mothers may think I am a bit 'snooty' because I don't want to talk, and I'm not like that. But I wouldn't want other TAs to talk about me or my family to their friends. How can I not be seen as 'snooty' and keep friends and keep confidentiality?

The social context: In this example, matters of confidentiality need to be taken into consideration. Privileged information can arise in many school situations, there is a need at all times to maintain professional discretion and confidentiality. In this situation, this Teaching Assistant is aware that exercising judgement, caution and tact may create the impression of being distant and unfriendly, perhaps even being disdainful of usual playground gossip, to the point of losing friendship patterns.

The individual person: Gina is confronted with a personal situation. She is friends with one of the parents but has to keep her professional practice separate. Being perceived as snooty is something over which she has little control.

\section{Further comments}

The six examples above are taken from two broad areas of professional work: the setting, social context and personal circumstances of trainers within a large organisation 
and of classroom teaching assistants within schools. Their situated reflective questions we have highlighted include:

- How will this affect me?

- What would I do?

- What is going to happen?

- How would I deal with that?

- How will I cope?

- How can I respond?

Our discussions of situated reflective practice entail those circumstances where change is visited upon the individual by forces outside their immediate control. For instance, in Example 1, Patrick is a passive observer of a phenomena, and worrying if he is not to be the next in line for 'forced retirement'; in Example 3, Alan is concerned about the loss to the community he serves, he experiences this by proxy. All of the examples are bounded by social and organisational conditions, where the locus of power is separate from the person experiencing it.

As noted above, we see such reflective questions as the result of deliberation, introspection and contemplation formed through variances between formulations and expectations of experience and what is then perceived to have taken place. In each of the six examples, something changed in the setting, social context or personal disposition of the individual, their reflections became situated, and surfaced in the conversational company of an 'empathetic other'.

We see reflective questions, then, as self-questions that show contemplation at work in a search for clarity, connection, introspection, evaluation and identity. Our research strongly suggests that self-questioning, prompted by the questioner's own situations, leads to deep, fundamental questions. Moreover, it shows (King 1994, Rosenshine et al., 1996) that self-questioning is an effective monitoring and regulating strategy for people as they survey the situations in which they find themselves. In this vein, Perkins (1995) suggests that 'reflective intelligence' helps people to face novel or complex problems with confidence, allowing the analysis of different components, consider past experience and choose from the many angles from which a solution might be approached. Self-reflective ability, says Perkins, is a control system for other kinds of intelligence. 
One characteristic of the questions listed above is that they look forward to an anticipated event and are akin to Nehring et al. (2010) idea of their experimental nature in relation to a continuing activity. They are questions that enable a person to consider an appropriate course of action, to plan. From this point they begin to consider options available to them, evaluating the possible outcomes. Reflecting on the situation and asking the question is an initial part of professional problem solving. At one level, it might appear fruitless to reflect forward since the event may never occur. A constant state of anxiety and self-examination over possible futures may not always be healthy.

The positive sense of SRP is that it can prepare an individual; it is a method of dealing with change management. People experience various emotions, reactions and concerns at times of anticipated change. The combination of these differs for each person and for any given situation but can include for example, perceptions of lack of control, feeling of loss and exclusion, fear of the unknown and feelings of unworthiness. SRP questioning has a place in this process of change so that, if an individual cannot see a way forward, then SRP may assist the thinking process. If the situation is anticipatory then, arguably, it may be difficult to know which questions to ask. The respondent's own questions can be received and responded to with the aim of supporting the thought process. In the case of mediation with an 'empathetic other' the respondent must be allowed to stay in their own model of the world as only they can make the best decisions for themselves at that time, based on their concerns. SR questioning is therefore not so much engendered by the actual anticipated change of a situation but mostly by the respondent's reaction to that change. The situation acts as a catalyst for the thought. 


\section{References}

Åkerlind, G.S. (2007). Constraints on academics' potential for developing as a teacher. Studies in Higher Education, 32, 21-37.

Bell, A \& Mladenovic R. (2013): How tutors understand and engage with reflective practices, Reflective Practice: International and Multidisciplinary Perspectives, 14(1), $1-11$

Bleakley, A. (1999): From reflective practice to holistic reflexivity, Studies in Higher Education, 24(3), 315-330

Boud, D. \& Miller, N. (1996). Working with experience: animating learning. London, Routledge.

Bourner, T. (2003). Assessing reflective learning. Education and Training, 45(5), 267272.

Cho, K, L. and Jonassen, D, H. (2002) The Effects of Argumentation Scaffolds on Argumentation and PRoblem Solving. Educational Technology Research and Development, ISSN 1042-1629, 01/2002, Volume 50, Issue 3, pp. 5 - 22

Chi, M.T.H., \& Glaser, R. (1985). Problem solving ability. In R. J. Steinberg (ed.), Human abilities: An information processing approach. New York: Freeman.

Chi, M.TH., Glaser, R. \& Farr, M. J. (eds.) (1988). The nature of expertise. Hillsdale, NJ: Erlbaum.

Cresswell, T. (2004). Place, A short introduction. Maiden, MA: Blackwell Publishing. Des Marchais, J. E., Bureau, M. A., Dumais, B., \& Pigeon, G. (1992). From traditional to problem-based learning: A case report of complete curriculum reform. Medical Education, 26, 190-199.

Dewey, J. (1933) How we think: a restatement of the relation of reflective thinking in the educative process. Boston: DC Heath and Co.

Frase, L., \& Schwartz, B. (1975). Effect of question production and answering on prose recall. Journal of Educational Psychology, 72(5), 628-635.

Gibbs G (1988). Learning by Doing: A guide to teaching and learning methods. Further Education Unit. Oxford Polytechnic: Oxford

Gillespie, C. (1990). Questions about student-generated questions. Journal of Reading, 34(4), 250-257. 
Glaubman, R., Ofir, L.\& Glaubman, H. (1997). Effects of self-directed learning, story comprehension, and self-questioning in Kindergarten. Journal of Educational Research 90(6), 361-374.

Gibbs G (1988). Learning by Doing: A guide to teaching and learning methods. Further Education Unit. Oxford Polytechnic: Oxford.

King, A. (1994a) Autonomy and question asking: the role of personal control in guided student-generated questioning. Learning and individual differences, 6, 163-185.

King, A. 1992. "Facilitating Elaborative Learning through Guided Student Generated Questioning." Educational Psychologist 27 (1): 11-126

King, A. (1994b). Guiding knowledge construction in the classroom: Effects of teaching children how to question and how to explain. American Educational Research Journal $31(2), 338-368$.

King, A. (1997). ASK to THINK-TELWHY ${ }^{\circledR}(\mathrm{C}$ : A model of transactive peer tutoring for scaffolding higher level complex learning. Educational Psychologist, 32(4), 221235.

Koe, H, N., Lee, C, B. and Teo, T. (2011) The Role of Self-Questioning-

Problem Solving in a Security Organisation. Systems Research and Behavioral

Science, ISSN 1092-7026, 01/2011, Volume 28, Issue 1, p. 91

Korthagen, F. \& Vasalos, A. (2005) Levels in reflection: core reflection as a means to enhance professional growth. Teachers and Teaching: Theory and Practice, 11(1), 4771.

Larkin, J., McDermott, J., Simon, D. \& Simon, H. A. (1980). Expert and novice performance in solving physics problems. Science, 208, 1335-1342.

Malthouse, R. (2012) Reflecting Blues: Perceptions of policing students with regard to reflective practice and associated skills. Saarbrücken: Lambert Academic Publishing. Malthouse, R. \& Roffey-Barentsen, J. (2013) Reflective Practice in Education and Trainng. London: Sage

Malthouse, R., Roffey-Barentsen J. \& Watts, M. (2013, in press) SRP

Marton, F. (1981) Phenomenography - Describing Conceptions of the World Around Us (1981) Instructional Science, ISSN 0020-4277, 07/1981, Volume 10, Issue 2, pp. $177-200$

Mckay, S. (1987). Cultural knowledge and the teaching of reading. Forum, 25(2), 18 20 .

Minott, M. (2010): Reflective teaching as self-directed professional development: 
building practical or work-related knowledge, Professional Development in Education, $36: 1-2,325-338$

Moon, J (2004) A Handbook of Reflective and experiential learning theory and practice. London: Routledge Falmer

Moran, D. (2008) Edmund Husserl. The Founder of Phenomenology. Cambridge: Polity Press

Nehring, J., Laboy, W \& Catarius, L., (2010): Connecting reflective practice, dialogic protocols, and professional learning. Professional Development in Education, 36:3, $399-420$

Palumbo, D. B. (1990). Programming language/problem-solving research: A review of relevant issues. Review of Educational Research, 60 (1), 65-89.

Pedrosa de Jesus, M. H., Watts, M. \& da Silva Lopes, B. (2009) Teaching approaches in higher education: the role of classroom questioning. In Fanghanel, J., Rege Colet, N. \& Bernstein, D. (eds) (2009) London Scholarship of Teaching and Learning 7th International Conference (2008) Proceedings, Volume 4, City University London, ISBN-978-0-9543742-4-2 .

Roth, G. (2004) Lessons from the Desert. Integrating managerial expertise and learning for organisational transformation. The Learning Organization, ISSN 09696474, 06/2004, Volume 11, Issue 3, pp. 194 - 208

Rosenshine, B., Meister, C. \& Chapman, S. (1996) Teaching students to generate questions: a review of the intervention studies. Review of Educational research, 66, $181-221$

Schön, D (1997) Educating the Reflective Practitioner. San Fransisco, CA: Jossey-Bass.

Smyth, J. (1992) Teachers work and the politics of reflection. American Educational Research Journal, 29 (2), 267-300.

Van der Meij, H. (1994) Student questioning: a componential analysis. Learning and individual differences, 6(2), 137-161.

Watts, D. M. \& Pedrosa, M. H. (2006) Enhancing University Teaching Through Effective Use of Questioning. London, SEDA Special 19 (Staff and Educational Development Association). ISBN: 1902435354.

Wong, B.Y.L. (1985). Self-questioning instructional research: A review. Review of Educational Research 55, 227-268. 